Canadian

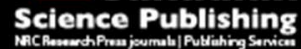

Canadian Journal of Microbiology Revue canadienne de de microbiologie

\title{
Screening of Ligninolytic Fungi for Biological Pretreatment of Lignocellulosic Biomass
}

\begin{tabular}{|r|l|}
\hline Journal: & Canadian Journal of Microbiology \\
\hline Manuscript ID & cjm-2015-0156.R1 \\
\hline Manuscript Type: & Article \\
\hline Date Submitted by the Author: & 29-Jun-2015 \\
\hline Kemplete List of Authors: & $\begin{array}{l}\text { Xu, Chunyan; Ningxia University, College of Life Science } \\
\text { Singh, Deepak; Washington State University, } \\
\text { Dorgan, Kathleen; Washington State University, } \\
\text { Zhang, Xiaoyu; Huazhong University of Science and Technology, } \\
\text { Chen, Shulin; Washington State University, }\end{array}$ \\
\hline barley straw, laccase, ligninolytic fungi, thermogravimetry analysis, \\
\hline
\end{tabular}

SCHOLARONE ${ }^{\text {IM }}$

Manuscripts 


\section{Screening of Ligninolytic Fungi for Biological Pretreatment of Lignocellulosic Biomass}

2

3

4

5

6

\section{8}

9

10

$11{ }^{*}$ Corresponding author.

12 Name: Shulin Chen

13

14

15

16 USA;
Chunyan $\mathrm{Xu}^{1,2}$, Deepak Singh ${ }^{2}$, Kathleen M. Dorgan ${ }^{2}$, Xiaoyu Zhang ${ }^{3}$, Shulin Chen ${ }^{2, *}$

${ }^{1}$ Key Laboratory of MOE for Protection and Utilization of Special Biological Resources in Western China, College of Life Science, Ningxia University, Yinchuan 750021, P.R. China;

${ }^{2}$ Department of Biological Systems Engineering, Washington State University, Pullman, WA 99164, USA;

${ }^{3}$ Key Laboratory of Molecular Biophysics of MOE, College of Life Science and Technology, Huazhong University of Science and Technology, Wuhan 430074, P.R. China

Postal address: Department of Biological Systems Engineering, Washington State University, Pullman, WA 99164,

E-mail address: chens@wsu.edu; Phone: 509-335-3743 
Abstract

In order to identify white rot fungi with high potential in biological pretreatment of lignocellulosic biomass, preliminary screening was carried out on plates by testing strains' abilities to oxidize guaiacol and decolorize the dyes, azure B and Poly R-478. Of the eighty six strains screened, sixteen were further used for secondary screening based on their ligninolytic ability. However, low manganese peroxidase activity and no lignin peroxidase activity were detected. Strain BBEL0970 was proved to be the most efficient in laccase production, which was finally identified as $T$. versicolor by the analysis of ribosomal DNA internal transcribed spacer gene sequence. Combining laccase production with biological pretreatment, the replacement of glucose with barley straw significantly improved the laccase activity up to $10.3 \mathrm{U} / \mathrm{ml}$, which provided evidence toward potential utilization of barley straw in laccase production by BBEL0970. Simultaneously, comparison in thermogravimetry analysis of the untreated and pretreated barley straw in liquid fermentation of laccase also demonstrated the high potential of BBEL0970 in biological pretreatment of lignocellulosic biomass. This work sheds light on further exploration on integrated process of lowcost laccase production and efficient biological pretreatment of barley straw by T. versicolor BBEL0970.

Key words: barley straw; laccase; ligninolytic fungi; thermogravimetry analysis; Trametes versicolor

\section{Introduction}

Concerns over fossil fuel supply and environmental issues have resulted in a large interest in researches relevant to renewable biofuel production from different lignocellulosic biomass, such as agricultural residues, forest products, and dedicated crops. Cellulose, hemicellulose and lignin are the main components present in the cell wall of lignocellulosic materials and the conversion of cellulose and hemicellulose to monomers is blocked by many physicochemical, compositional and structural factors. Various pretreatments, including chemical, biological, physical, and combinations thereof, are employed to deconstruct the plant cell wall and increase the accessibility of enzymes to cellulose. Biological pretreatment is considered as promising desirable pretreatment technologies owing to its environmental friendliness and lower energy consumption (Ruqayyah et al. 2013; Song et al. 2013; Wang et al. 2013).

White rot fungi, well-known lignocellulosic decomposers in ecological processes, play a key role in the decomposition of woody debris and have attracted particular attention due to their great capability for delignification. The principal mechanisms responsible for lignin degradation by white rot fungi involve ligninolytic enzymes, mainly 

including laccase, manganese peroxidase (MnP), and lignin peroxidase (LiP) (Ferhan et al. 2013). Ligninolytic enzymes are produced during secondary metabolism. Frequently, more than one isoform of ligninolytic enzymes is expressed under different culture conditions (Dhouib et al. 2005). A variety of research indicates that the production of ligninolytic enzymes is species- and strain-dependent (Elisashvili and Kachlishvilia 2009), therefore the discovery and selection of new organisms with higher delignification efficiency are both possible and necessary. During recent years, several studies have focused on exploring new or potentially powerful white rot fungi from various natural habitats (Dhouib et al. 2005). We selected the Olympic National Park in Washington State as the sampling site for the collection of ligninolytic fungi, which might be of high potential in biological pretreatment of lignocellulosic materials. Studies on fungal diversity in Washington State are attracting more and more interest (Edmonds and Lebo 1998; Hoff et al. 2004), and basidiomycetes diversity has also been reported in the Olympic National Park (Edmonds and Lebo 1998), which boasts mild temperatures, high amounts of precipitation, and outstanding biodiversity (Van Pelt et al. 2006). However, there is no report on the isolation and screening of white rot fungi from this particular habitat for biological pretreatment of lignocellulosic biomass.

In this study, we more specifically aimed: 1) to screen ligninolytic white rot fungi with high enzyme activities and to enhance the enzyme production by the replacement of glucose with barley straw, and 2) to illustrate the effect of biological pretreatment via TG/DTG analysis of the untreated and pretreated barley straw by the objective fungal strain. The process we used is summarized in the experimental flowchart Fig. 1.

\section{Materials and methods}

\section{Organisms}

Fungal fruiting bodies and decayed wood were collected from the Olympic National Park on the peninsula of Washington State. Eighty six fungal strains with different morphotypes were isolated and purified by placing pieces of each specimen on PDA (potato dextrose agar) medium. The pure cultures were preserved on PDA slants at $4{ }^{\circ} \mathrm{C}$ and activated at $28^{\circ} \mathrm{C}$ on PDA plates for one week before use.

Primary screening on solid media

To evaluate the ability of the 86 fungal strains (named BBEL0901 to BBEL0986) to produce lignin-degrading enzymes, guaiacol oxidation and dye decolorization were employed as initial screening methods. Screening was carried out in Petri dishes (90 mm diameter) with approximately $14 \mathrm{ml}$ of BSM (basal solid medium) containing indicators. The BSM medium composition was as follows: $10.0 \mathrm{~g} / 1$ glucose, $0.2 \mathrm{~g} / 1 \mathrm{KH}_{2} \mathrm{PO}_{4}, 0.05 \mathrm{~g} / 1 \mathrm{MgSO}_{4} \cdot 7 \mathrm{H}_{2} \mathrm{O}$, 
Tween 80, $1.5 \mathrm{mmol} / \mathrm{l}$ veratryl alcohol, $20 \mathrm{~g} / 1$ agar and $10 \mathrm{ml} / 1$ trace elements. The trace elements contained $80 \mathrm{mg} / 1$ $\mathrm{CuSO}_{4} \cdot 5 \mathrm{H}_{2} \mathrm{O}, 50 \mathrm{mg} / 1 \mathrm{Na}_{2} \mathrm{MoO}_{4} \cdot 2 \mathrm{H}_{2} \mathrm{O}, 33 \mathrm{mg} / 1 \mathrm{MnSO}_{4} \cdot \mathrm{H}_{2} \mathrm{O}, 43 \mathrm{mg} / 1 \mathrm{ZnSO} \cdot \cdot 7 \mathrm{H}_{2} \mathrm{O}, 50 \mathrm{mg} / 1 \mathrm{FeSO} \cdot \cdot 7 \mathrm{H}_{2} \mathrm{O} . \mathrm{Glucose}$ thiamine, Tween 80 , veratryl alcohol and trace elements were filter sterilized and added after autoclaving, as was the indicator compound guaiacol $(0.1 \mathrm{~g} / \mathrm{l})$. Two dye indicators, azure B $(0.1 \mathrm{~g} / \mathrm{l})$ and Poly R-478 $(0.1 \mathrm{~g} / \mathrm{l})$, were added to the media before autoclaving.

Three 5-mm diameter agar plugs of active mycelia pre-cultured on PDA plates were inoculated onto BSM plates containing the indicators. All plates were incubated at $28{ }^{\circ} \mathrm{C}$ for 2 weeks. In presence of guaiacol the ligninolytic enzyme positive strains can be detected by the formation of a reddish-brown halo. The ligninolytic enzymes can also be observed as a colorless zone around the fungal colonies on the BSM plates with dyes. Secondary screening by liquid culture Sixteen ligninolytic enzyme positive strains selected during primary screening were further screened in liquid medium for laccase, LiP, and $\mathrm{MnP}$ activity. Ten agar plugs (3 $\mathrm{mm}$ in diameter) of the selected strains were inoculated into 500-ml Erlenmeyer flasks containing $100 \mathrm{ml}$ of the BLM (basal liquid medium). BLM is BSM without agar. All strains were grown in triplicate at $28^{\circ} \mathrm{C}$ and $150 \mathrm{rpm}$ for 2 weeks. Ligninolytic enzymes (laccase, $\mathrm{MnP}$, and LiP) were determined every two days in triplicate.

Biological pretreatment of barley straw and improvement of laccase activity

Barley straw powder (particles between $0.425 \mathrm{~mm}$ and $0.850 \mathrm{~mm}$ ) from Washington State was used for biological pretreatment by Trametes versicolor BBEL0970. The pre-grown fungal mycelia in Potato Dextrose Broth (PDB) were collected and washed via centrifugation. The washed mycelia were then inoculated into sterile barley straw medium, the composition of which was the same with BLM except that glucose was replaced with barley straw. The fungus was cultured in 500-ml Erlenmeyer flasks at $28{ }^{\circ} \mathrm{C}$ and $150 \mathrm{rpm}$ for 24 days and all the experiments were performed in triplicate. The pretreated barley straw was collected and oven-dried at $65^{\circ} \mathrm{C}$ for thermogravimetric (TG) analysis. Simultaneously, the fermentation broth was collected every two days by filtration and centrifugation for determination of laccase activity.

\section{Enzyme assays}

For laccase activity, 2, 2'-azino-bis-(3-ethylbenzothiazoline-6-sulphonic acid) (ABTS, Sigma) was used as the substrate (More et al. 2011). The assay mixture ( $1 \mathrm{ml}$ ) contained $100 \mathrm{mM}$ buffer, $1 \mathrm{mM}$ ABTS (final concentration), 
and $20 \mu \mathrm{l}$ appropriately diluted crude enzyme. For screening, laccase was assayed in acetic acid-sodium acetate buffer at $\mathrm{pH}$ 4.5. For optimal $\mathrm{pH}$ assay of different laccases, enzyme activity was assayed in different buffers as described below. The absorbance increase of assay mixture was monitored at $420 \mathrm{~nm}\left(\varepsilon_{420}=36.0 / \mathrm{mM} / \mathrm{cm}\right)$ in a UVvisible spectrophotometer.

MnP activity was assayed by the oxidation of $1 \mathrm{mM} \mathrm{MnSO}_{4}$ in $50 \mathrm{mM}$ sodium malonate (pH 4.5), in the presence of $0.1 \mathrm{mM} \mathrm{H} \mathrm{H}_{2} \mathrm{O}_{2}$. Manganic ions $\left(\mathrm{Mn}^{3+}\right)$, form a complex with malonate, which absorbs at $270 \mathrm{~nm}\left(\varepsilon_{270}=11.59\right.$ $/ \mathrm{mM} / \mathrm{cm}$ ) (Murugesan et al. 2007).

Determination of LiP was performed by monitoring the decolorization of azure B according to Archibald (Archibald 1992). The assay mixture $(1 \mathrm{ml})$ contained $32 \mu \mathrm{M}$ azure $\mathrm{B}$ (final concentration) and $100 \mu \mathrm{M} \mathrm{H}_{2} \mathrm{O}_{2}$ in $50 \mathrm{mM}$ sodium tartrate buffer ( $\mathrm{pH} 4.5)$. The reaction was initiated by adding hydrogen peroxide and the optical density decrease was monitored at $651 \mathrm{~nm}\left(\varepsilon_{651}=48.8 / \mathrm{mM} / \mathrm{cm}\right)$. Enzyme reactions were performed in triplicate and controls were carried out without the addition of enzyme or $\mathrm{H}_{2} \mathrm{O}_{2}$. The enzyme activities were expressed as international units (U), defined as the amount of enzyme needed to produce $1 \mu \mathrm{mol}$ of products per minute at $30^{\circ} \mathrm{C}$ and presented as $\mathrm{U} / \mathrm{ml}$.

TG analysis

TG analysis was conducted in a Mettler-Toledo TG analyzer (TGA/SDTA851 ${ }^{\mathrm{e}}$, Mettler-Toledo, Inc., Columbus, $\mathrm{OH})$. Approximately $6 \mathrm{mg}$ of each sample was loaded into an open alumina pan and TG analysis was carried out at the heating rate of $10{ }^{\circ} \mathrm{C} / \mathrm{min}$, with the decomposition range being from $25{ }^{\circ} \mathrm{C}$ to $600{ }^{\circ} \mathrm{C}$. The inert gas for thermogravimetric experiments was nitrogen with a flow rate of $20 \mathrm{ml} / \mathrm{min}$. In order to avoid unexpected oxidative decomposition, nitrogen was used to purge the furnace for $2 \mathrm{~h}$ to establish an inert environment before starting each run. To verify the reproducibility of weight loss curves, duplicate runs of each sample were performed under the same experimental conditions. The approximate overlapping of two weight loss curves from two separate test runs was considered as reasonable agreement. Otherwise, another two runs were performed then to determine which one should be chosen. Differential thermogravimetry (DTG) curves were calculated on basis of the TG data of each sample. The untreated material was used as the control sample.

\section{Molecular identification}

Fungal DNA was isolated from liquid nitrogen frozen mycelia with CTAB (cetyltrimethyl ammonium bromide) in the presence of $\beta$-mercaptoethanol and polyvinylpyrrolidone, followed by organic extractions and isopropanol precipitation (Jasalavich et al. 2000). The ITS (internal transcription spacers) region of the ribosomal DNA was 
amplified by PCR from extracted DNA using the primer pair of ITS1 (TCC GTA GGT GAA CCT GCG G) and ITS4 (TCC TCC GCT TAT TGA TAT GC). The fragments obtained were approximately $700 \mathrm{bp}$ based on agarose gel electrophoresis. Prior to sequencing, the PCR products were cleaned using a QIAquick PCR purification column (Qiagen GmbH, Hilden, Germany) according to the manufacturer's recommendations. The purified fragments were then cloned using the pGEM® -T Easy Vector Systems (Promega) and sequenced using primers T7 and SP6. The consensus sequences obtained were corrected manually for errors and the most homologous sequences were compared with those in the National Center for Biotechnology Information Nucleotide Sequence Database by using the Basic Local Alignment Search Tool (BLAST) algorithm (http://www.ncbi.nlm.nih.gov/blast).

\section{Results}

Primary screening on BSM plates

Fig. 2 shows guaiacol oxidation and dye decolorization on plates with the characteristic halo zones displayed by strains BBEL0901, BBEL0902, BBEL0922, BBEL0958, BBEL0968, BBEL0970, and BBEL0973. Of the 86 strains tested on BSM plates, $16(18.6 \%)$ and $73(84.9 \%)$ strains showed Poly R-478 and azure B decolorization, respectively. $21(24.4 \%)$ of the 86 strains exhibited the ability to oxidate guaiacol, and most reddish-brown halos appeared earlier (about 1-3 days) than dyes decolorization. Four strains (BBEL0901, BBEL0902, BBEL0958, and BBEL0973) showed considerably higher abilities to completely decolorize Poly R-478 within 2 weeks with homogeneous decolorization pattern (Fig. 2e through 2h). Azure B was more easily degraded than Poly R-478 because all strains able to decolorize Poly R-478 could also degrade azure B, while all strains able to degrade azure B were not able to decolorize Poly R-478. According to the results on primary screening plates, sixteen strains that showed deep decolorization of the dyes or a dark color reaction with guaiacol were selected for secondary evaluation in liquid culture (Table 1).

Ligninolytic characterization of the sixteen strains

Upon fermentation, no LiP activity was detected in any of the strains. MnP activity was detected in 12 strains of the 16 strains tested; however, the activities were very low (Data not shown). For laccase, five of the sixteen strains (BBEL0901, BBEL0902, BBEL0970, BBEL0972 and BBEL0973) were able to produce detectable extracellular laccase and the level of laccase activities varied significantly among the fungi tested (Fig. 3), which might be due to the difference of strain taxa and characteristics. The laccase activity of BBEL0970 was notably higher than the other four laccase producers, and the highest level of activity reached $3.14 \mathrm{U} / \mathrm{ml}$ after 8 days of fermentation. The result of 
157 ligninolytic enzyme activities in liquid culture indicated that strain BBEL0970 was a potential strain with higher 158 laccase activity and was therefore chosen for the following biological pretreatment. The effect of $\mathrm{pH}$ value on the 159 laccase actvity showed that the laccase preferred acidic conditions for substrate (ABTS) transformation, with the optimum $\mathrm{pH}$ of 2.5 and higher relative activities over a broad $\mathrm{pH}$ range from 1.8 to 4.0 , which is undoubtedly 161 favorable for biotechnological application.

162 Based on the performance on plates and enzyme production in liquid culture, an attempt was made to correlate decolorization or color reaction with the activity of ligninolytic enzymes. Combined Table 1 and Fig. 3, it is obvious that the ability to oxidize guaiacol and laccase activity appeared to be directly correlated. The five strains which generated dark reddish-brown halos on the guaiacol plates demonstrated higher laccase activities. Therefore, guaiacol oxidation on plates can be used as a simple and inexpensive method for screening for laccase producing fungal strains. However, there is no correlation between the special substrate and the special strain that can produce $\mathrm{MnP}$ and LiP. Improper culture condition might be the main reason of low or no $\mathrm{MnP}$ and LiP activities. It was reported that shaken condition is more suitable than stationary condition for laccase production, however, MnP and LiP production was higher under stationary culture than agitation condition (Dhouib et al. 2005).

171 Enhanced laccase production under ligninolytic condition

172 Comparison of laccase production under different conditions with barley straw and glucose, respectively, as the sole 173 carbon source was conducted in this part. Results displayed in Fig. 4 showed laccase production with prolonged 174 incubation times were rather different between the two conditions. Based on the mycelium growth, strain BBEL0970 accumulated principally biomass during the initial 12 days in glucose medium. The laccase activity increased sharply when glucose was exhausted, reached the highest level $(6.5 \mathrm{U} / \mathrm{ml})$ on the $20^{\text {th }}$ day, and decreased quickly afterwards,

177 with an activity of $2.4 \mathrm{U} / \mathrm{ml}$ on the $24^{\text {th }}$ day. While in barley straw medium, the laccase activity was noticeably 178 enhanced starting on the $6^{\text {th }}$ day and remained at high level throughout fermentation, with a maximum of $10.3 \mathrm{U} / \mathrm{ml}$ 179 on the $20^{\text {th }}$ day, which was $58.5 \%$ higher than that of glucose. The fluctuation of the laccase activity between 5.2 $\mathrm{U} / \mathrm{ml}$ and $10.3 \mathrm{U} / \mathrm{ml}$ provides a hint of relationship between biodegradation of barley straw and laccase production by BBEL0970. The high laccase activity in barley straw medium also alludes to biodelignification of lignocellulosic biomass and biodegradation of xenobiotics. 
TG analysis is a commonly used technique to study thermal events during pyrolysis of biomass and it can be used primarily to determine the composition of materials (Aboulkas and El Harfi 2009). Therefore, the TG Analysis was designed for verifying the efficiency of the strain BBEL0970 in biological pretreatment of biomass. The TG thermograms and derivative thermogravimetry (DTG) curves of the control and pretreated samples by the strain BBEL0970 are shown in Fig. 5A and 5B, respectively. It can be observed that both of the samples showed the typical decomposition behavior of lignocellulosic biomass with three stages of weight loss during the overall process, with the moisture loss occurred up to approximately $150{ }^{\circ} \mathrm{C}$ followed by active pyrolysis and passive pyrolysis. It's reported that hemicellulose, cellulose, and lignin are decomposed at 150-300, 275-300, and 250-500 ${ }^{\circ} \mathrm{C}$, respectively. Therefore, the shoulder peak of the DTG curve at low temperature around $250{ }^{\circ} \mathrm{C}$ is generally considered as the result of thermal degradation of hemicellulose, the main successive weight loss around $330^{\circ} \mathrm{C}$ by cellulose, and the long tail at high temperature corresponds to lignin volatilization. Difference between the control and pretreated samples arose distinctly at the active pyrolysis stage (Fig. 5B), resulting mainly from the thermal decomposition of cellulose and hemicellulose. The hemicellulose shoulder peak of the control sample was overlapped in the cellulose main peak (peak b) and it's hard to be observed. After biological pretreatment, the overlapping between devolatilization peaks of cellulose and hemicellulose was reduced and the main decomposition peak (peak a) shifted evidently to higher temperature, resulting in an obvious shoulder peak (peak c) at low temperature. This difference indicates the obvious changes on thermal behaviors of cellulose and hemicellulose after biological pretreatment with BBEL0970.

Based on the data from TG and DTG curves, the integral method of Coats and Redfern (1964), which has been successfully used for research on the decomposition kinetics of solid substrate, was used to determine the apparent activation energy of decomposition at different temperatures. The results on kinetics parameters of thermal decomposition of the control and pretreated samples are shown in Table 2. As shown in Table 2, the pyrolytic characteristics of both barley straw samples could fit the kinetics model well, with all $\mathrm{R}^{2}$ values being above 0.9 . The start devolatilization temperature shifted obviously to higher temperature after biological pretreatment which might be due to the consumption of simple nutrition in barley straw by BBEL0970. The activation energy at low temperatures decreased from $15.18 \mathrm{~kJ} / \mathrm{mol}$ to $13.44 \mathrm{~kJ} / \mathrm{mol}$ after biological pretreatment, which might be caused by biological degradation of hemicellulose after pretreatment with the fungus. The conversion ratios during this period were also decreased obviously from $13.39 \%$ to $5.16 \%$, which strongly suggested the degradation and deconstruction 
212 of hemicellulose. At the stage for decomposition of main components $\left(250-350{ }^{\circ} \mathrm{C}\right.$ for the control sample and 250 -

$213400{ }^{\circ} \mathrm{C}$ for the pretreated sample), more than $80 \%$ of the devolatilization part for both samples was devolatilized and

214 the activation energy was slightly increased from $65.56 \mathrm{~kJ} / \mathrm{mol}$ to $71.81 \mathrm{~kJ} / \mathrm{mol}$ which might be caused by

215 biodegradation of armphous cellulose by the white rot fungus. Notable decreases on the activation energy and preexponential factor at high temperatures $\left(350-550{ }^{\circ} \mathrm{C}\right.$ for the control sample and $400-550{ }^{\circ} \mathrm{C}$ for the pretreated sample) were observed between the pretreated and control samples, indicating easier devolatilization of lignin after biological pretreatment.

Strain identification of strain BBEL0970

The morphological characters of the fruit body of the srtain BBEL0970 (leathery texture, cap with rust-brown zones) resembled that of common wood-decaying fungi, Trametes versicolor. The molecular identification of the srtain BBEL0970 was performed by internal transcribed spacer (ITS) sequencing. The apparent size of PCR amplication products was about $700 \mathrm{bp}$. A comparative analysis of the ITS sequence by BLASTn, Clustalx and Mega2 software with the neighbor-joining method revealed that the strain BBEL0970 was enrolled into a cluster containing and was found to be nearly identical to $T$. versicolor UBCF20357 (Fig. 6) with more than 99\% sequenece similarity. It was therefore identified as T. versicolor BBEL0970. The submitted nucleotide sequence was provided a GenBank accession number KM819087.

\section{Discussion}

Ligninolytic fungi, which have the ability of degrade lignin, are of particular interest during the past several decades. Tremendous attention has been paid to screening of ligninolytic fungi due to the important application of ligninolytic enzymes in biotechnological and environmental processes (Chander et al. 2014; Manavalan et al. 2015). Many compounds have been employed in strain screening of ligninolytic fungi and guaiacol is one of the indicators commonly used. Ligninolytic enzymes produced by fungi can turn guaiacol reddish-brown, showing a nonhomogeneous oxidation pattern. Similarly, azure B (an azo dye) is adopted in LiP enzyme activity determination on the basis of its decolorization. (1992). Another polymeric dye, Poly R-478 (polyanthraquinone, which is a polyvinylamine sulfonated backbone with an anthrapyridone chromophore), bears some structural similarity to lignin and changes color when transformed via biological oxidation (Moreira et al. 2004). Thus, azure B and Poly R-478 can also act as indicators identifying microbial cultures capable of degrading colored organics and related molecules with aromatic structures. Results of our research suggested that guaiacol was oxidized by white rot fungi much 
earlier than the dyes were decolorized, which demonstrated that it was more efficient to use guaiacol as the indicator for screening of ligninolytic white rot fungi. The screened $T$. versicolor is one of the most common white rot fungi in North America and has the high potential in lignin biodegradation. As a typical basidiomycete that can produce three ligninolytic enzymes, T. versicolor BBEL0970 produces laccase as the predominant ligninolytic enzyme.

Increase of laccase production will contribute to high amounts of laccase needed for industrial applications as well as lignin degradation. As a secondary metabolite, laccase production is highly dependent on the culture conditions of the fungus. Laccase activity can be influenced by many factors, such as inducers, $\mathrm{pH}$, aeration and various nutritional effects (Dhouib et al. 2005). The growing demand of laccase application in biotechnology has brought about more studies on its production at commercially viable prices. Utilization of lignocellulosic wastes in laccase production reduces the production cost and simultaneously provides a promising way of converting agricultural residues into high-value products (Risna and Suhirman 2002). In recent years, various lignocellulosic agricultural residues, such as rice bran, wheat bran, and barley bran have been suggested as substitute carbon sources or inducers for ligninolytic enzyme production by white rot fungi (Tišma et al. 2012; Cambria et al. 2011; Aydinoğlu and Sargin 2013). Although laccase activity in $T$. versicolor could be enhanced considerably by taking rice bran as carbon source, the activity was only $22 \mathrm{U} / \mathrm{g}$ of bran (Chawachart et al. 2004). The combined effect of xylidine addition and glucose suppression with solid lignin induction enhanced laccase activity of $T$. versicolor to $1.58 \mathrm{U} / \mathrm{ml}$ (Xavier et al. 2007). This work explores the combination of laccase production utilizing barley straw as the sole carbon resource and biological pretreatment of barley straw by BBEL0970 in liquid fermentation. The changes in composition of the pretreated barley straw via TG analysis implied the modification of lignocellulose as well as the induction of barley straw to laccase. Laccase production with barley straw rather than glucose as the sole carbon source is of great significance for its commercial utilization. Compared with reported effects from other biomass, our result gave the most predominant increase in laccase activity, which reached $1030 \mathrm{U} / \mathrm{g}$ of barley straw, suggesting high potential for laccase production from barley straw. In addition to acting as the carbon source for fungal growth, lignocellulose might also play the role of an inducer in laccase production and stabilizer in laccase activity (Tišma et al. 2012). The concentration of inducers present in the barley straw medium is rather low, so there is the possibility of improving laccase production by increasing the inducer concentration or adding other inducers. Moreover, it was reported that a higher yield of laccase could be achieved by $T$. versicolor in nitrogen rich media rather than nitrogen limited media (Heinzkill et al. 1998). Therefore, intensive studies on adjusting the inducers and carbon to nitrogen ratio will be 
favorable for enhancing and inducing laccase production by BBEL0970 using barley straw. Moreover, the present work is bringing out further exploration on integrated process of low-cost laccase production and efficient pretreatment of barley straw in solid-state fermentation.

\section{References}

Aboulkas, A., and El Harfi, K. 2009. Co-pyrolysis of olive residue with poly(vinyl chloride) using thermogravimetric analysis. J. Therm. Anal. Calorim. 95(3): 1007-1013.

Archibald, F.S. 1992. A new assay for lignin-type peroxidases employing the dye Azure B. Appl. Environ. Microbiol. 58(9): $3110-3116$.

Aydinoğlu, T., and Sargin, S. 2013. Production of laccase from Trametes versicolor by solid-state fermentation using olive leaves as a phenolic substrate. Bioprocess Biosyst. Eng. 36(2): 215-222.

Cambria, M.T., Ragusa, S., Calabrese, V., and Cambria, A. 2011. Enhanced laccase production in white-rot fungus Rigidoporus lignosus by the addition of selected phenolic and aromatic compounds. Appl. Biochem. Biotechnol. 163(3): 415-422.

Chander, M., Singh, D., and Kaur, R. 2014. Biodecolourisation of reactive red an industrial dye by Phlebia spp. J. Environ. Biol. 35(6): 1031-1036.

Chawachart, N., Khanongnuch, C., Watanabe, T., and Lumyong, S. 2004. Rice bran as an efficient substrate for laccase production from thermotolerant basidiomycete Coriolus versicolor strain RC3. Fungal Divers. 15: 23-32.

Coats, A.V., and Redfern, J.P. 1964. Kinetic parameters from thermogravimetric data. Nature 201: 68-69.

Dhouib, A., Hamza, M., Zouari, H., Mechichi, T., Hmidi, R., Labat M., et al. 2005. Screening for ligninolytic enzyme production by diverse fungi from Tunisia. World J. Microbiol. Biotechnol. 21: 1415-1423.

Edmonds, R.L., and Lebo, D.S. 1998. Diversity, production, and nutrient dynamics of fungal sporocarps on logs in an old-growth temperate rain forest, Olympic National Park, Washington. Can. J. For. Res. 28: 665-673.

Elisashvili, V., and Kachlishvilia, E. 2009. Physiological regulation of laccase and manganese peroxidase production by white-rot Basidiomycetes. J. Biotechnol. 144(1): 37-42.

Ferhan, M., Santos, S.N., Melo, I.S., Yan, N., and Sain, M. 2013. Identification of a potential fungal species by 18S rDNA for ligninases production. World J. Microbiol. Biotechnol. 29(12): 2437-2440.

Heinzkill, M., Bech, L., Halkier, T., Schneider, P., and Anke, T. 1998. Characterization of laccases and peroxidases from wood-rotting fungi (family Coprinaceae). Appl. Environ. Microbiol. 64(5): 1601-1606. 
Hoff, J.A., Kloppenstein, N.B., McDonald, G.I., Tonn, J.R., Kim, M.S., Zambino, P.J., et al. 2004. Fungal endophytes in woody roots of Douglas-fir (Pseudotsuga menziesii) and ponderosa pine (Pinus ponderosa). Forest Pathol. 34: 255-271.

Jasalavich, C.A., Ostrofsky, A., and Jellison, J. 2000. Detection and identification of decay fungi in spruce wood by restriction fragment length polymorphism analysis of amplified genes encoding rRNA. Appl. Environ. Microbiol. 66(11): 4725-4734.

Manavalan, T., Manavalan, A., and Heese, K. 2015. Characterization of lignocellulolytic enzymes from white-rot fungi. Curr. Microbiol. 70(4): 485-498.

More, S.S., Renuka, P.S., Pruthvi, K., Swetha, M., and Malini, S., and Veena, S.M. 2011. Isolation, purification, and characterization of fungal laccase from Pleurotus sp. Enzyme Res. 2011: 1-7.

Moreira, M.T., Viacava, C., and Vidal, G. 2004. Fed-batch decolorization of Poly R-478 by Trametes versicolor. Braz. Arch. Biol. Technol. 47: 179-183.

Murugesan, K., Nam, I.H., Kim, Y.M., and Chang, Y.S. 2007. Decolorization of reactive dyes by a thermostable laccase produced by Ganoderma lucidum in solid state culture. Enzyme Microb. Techol. 40: 1662-1672.

Risna, R.A., and Suhirman. 2002. Ligninolytic enzyme production by Polyporeceae from Lombok, Indonesia. Fungal Divers. 9: 123-134.

Ruqayyah, T.I.D., Jamal, P., Alam, M.Z., and Mirghani, M.E. 2013. Biodegradation potential and ligninolytic enzyme activity of two locally isolated Panus tigrinus strains on selected agro-industrial wastes. J. Environ. Manage 118: $115-121$.

Song, L., Ma, F., Zeng, Y., Zhang, X., and Yu, H. 2013. The promoting effects of manganese on biological pretreatment with Irpex lacteus and enzymatic hydrolysis of corn stover. Bioresour. Technol. 135: 89-92.

Tišma, M., Znidaršič-Plazl, P., Vasić-Rački, D., and Zelić, B. 2012. Optimization of laccase production by Trametes versicolor cultivated on industrial waste. Appl. Biochem. Biotechnol. 166(1): 36-46.

Van Pelt, R., O'Keefe, T.C., Latterell, J.J., and Naiman, R.J. (2006) Riparian forest stand development along the Queets River in Olympic National Park, Washington. Ecol. Monogr. 76: 277-298.

Wang, F.Q., Xie, H., Chen, W., Wang, E.T., Du, F.G., and Song, A.D. 2013. Biological pretreatment of corn stover with ligninolytic enzyme for high efficient enzymatic hydrolysis. Bioresour. Technol. 144: 572-578. 
323 Xavier, A., Tavares, A.P.M., Ferreira, R., and Amado, F. 2007. Trametes versicolor growth and laccase induction 324 with by-products of pulp and paper industry. Electron. J. Biotechnol. 10: 444-451.

325 
327 Table 1 Sixteen strains selected for secondary screening

\begin{tabular}{|c|c|c|c|c|}
\hline \multirow[b]{2}{*}{ Strain } & \multicolumn{3}{|c|}{ Indicators } & \multirow[b]{2}{*}{ Original specimens } \\
\hline & $\begin{array}{c}\text { Poly R- } \\
478\end{array}$ & Guaiacol & $\begin{array}{c}\text { Azure } \\
\text { B }\end{array}$ & \\
\hline BBEL0901 & $+/ *(9)$ & $+/ *$ & $+/ *$ & white-rotted wood \\
\hline BBEL0902 & $+/ *(8.5)$ & $+/ *$ & $+/ *$ & white-rotted wood \\
\hline BBEL0907 & - & - & $+/ *$ & brown-rotted wood \\
\hline BBEL0909 & + & - & $+/ *$ & white-rotted wood \\
\hline BBEL0919 & - & + & $+/ *$ & meaty bright yellow fruiting body, a thin stem, a small cap \\
\hline BBEL0921 & - & - & $+/ *$ & hard fruiting body, round, black upside, white underside \\
\hline BBEL0922 & - & $+/-$ & $+/ *$ & $\begin{array}{l}\text { woody fruiting body, semicircular, light brown surface, white } \\
\text { underside }\end{array}$ \\
\hline BBEL0925 & + & - & $+/ *$ & fibrotic fruiting body, yellow surface, milky white underside, \\
\hline BBEL0935 & - & - & $+/ *$ & tough fruiting body, grey cap, brown zones \\
\hline BBEL0952 & - & - & $+/ *$ & horse's hoof-like fruiting body, hard, deepred, rounded margin \\
\hline BBEL0958 & $+/ *(8)$ & + & $+/ *(7)$ & white-rotted wood \\
\hline BBEL0968 & + & - & $+/ *$ & hoof-like fruiting body, shiny surface, cinnamon brown \\
\hline BBEL0970 & - & $+/ *$ & - & fruiting body, leathery texture, rust-brown zones \\
\hline BBEL0972 & - & $+/ *$ & $+/ *$ & white-rotted wood \\
\hline BBEL0973 & $+/ *(12)$ & $+/ *$ & $+/ *$ & white-rotted wood \\
\hline BBEL0979 & + & - & $+/ *$ & fruiting body, semicircular cap, whitish zones \\
\hline
\end{tabular}

328 Notes: - Undetected color changes; +/- Light reddish-brown on guaiacol plates or slight decolorization of azure B 329 and Poly R-478; + Moderate reddish-brown on guaiacol plates or moderate decolorization of azure B and Poly R-478; $330+/ *$ Dark reddish-brown on guaiacol plates or deep decolorization of azure B and Poly R-478; Values in parentheses mean the day on which Poly R-478 or azure B was completely decolorized. 
Table 2 Kinetics parameters of wheat straw pyrolysis

\begin{tabular}{cccccc}
\hline Sample & $\mathrm{T} /{ }^{\circ} \mathrm{C}$ & $\alpha / \%$ & $E(\mathrm{~kJ} / \mathrm{mol})$ & $A(/ \mathrm{s})$ & $\mathrm{R}^{2}$ \\
\hline \multirow{2}{*}{ Control } & $200-250$ & $7.76-13.39$ & 15.18 & 0.30 & 0.946 \\
& $250-350$ & $13.39-83.64$ & 65.56 & $1.17 \times 10^{5}$ & 0.983 \\
& $350-550$ & $83.64-98.54$ & 5.12 & 0.08 & 0.985 \\
& $230-250$ & $4.21-5.16$ & 13.44 & 0.07 & 0.937 \\
Pretreated & $250-400$ & $5.16-92.99$ & 71.81 & $2.18 \times 10^{5}$ & 0.992 \\
& $400-550$ & $92.99-98.84$ & 2.91 & 0.04 & 0.979 \\
\hline
\end{tabular}

335

336 
337

338

339

340

341

342

343

\section{Figure Captions}

Fig. 1. Flowchart of isolation and screening of ligninolytic fungi for biological pretreatment of lignocellulosic biomass

Fig. 2. Changes on screening plates caused by positive lignin-degrading strains (a) guaiacol oxidation by BBEL0902 (4 days), (b) guaiacol oxidation by BBEL0970 (4 days), (c) azure B decolorization by BBEL0968 (14 days), (d) azure B decolorization by BBEL0922 (14 days), (e) Poly R-478 decolorization by BBEL0901 (7 days), (f) Poly R478 decolorization by BBEL0902 (7 days), (g) Poly R-478 decolorization by BBEL0958 (8 days), (h) Poly R-478 decolorization by BBEL0973 (7 days).

Fig. 3. Time courses of laccase activities in BLM. ( $\boldsymbol{\Delta})$ BBEL0901, ( ) BBEL0902, ( $\bullet$ BBEL0970, (घ) BBEL0972, and $(\triangle)$ BBEL0973.

Fig. 4. Laccase production by BBEL0970 under different conditions with barley straw and glucose, respectively, as the sole carbon source in production media.

Fig. 5. TG/DTG curves of the control and pretreated barley straw by BBEL0970. (A) TG curves, (B) DTG curves Fig. 6. Phylogenetic relationship among BBEL0970 and relative strains based on the ITS rDNA gene sequences. Phanerochaete chrysosporium was used as the control strain. All bootstrap values $>50 \%$ are shown at nodes based on 1,000 replications. Sequences accession numbers were retrieved from GenBank. 
Strain isolation of the Specimens from the Olympic

National Park in Washington State, USA

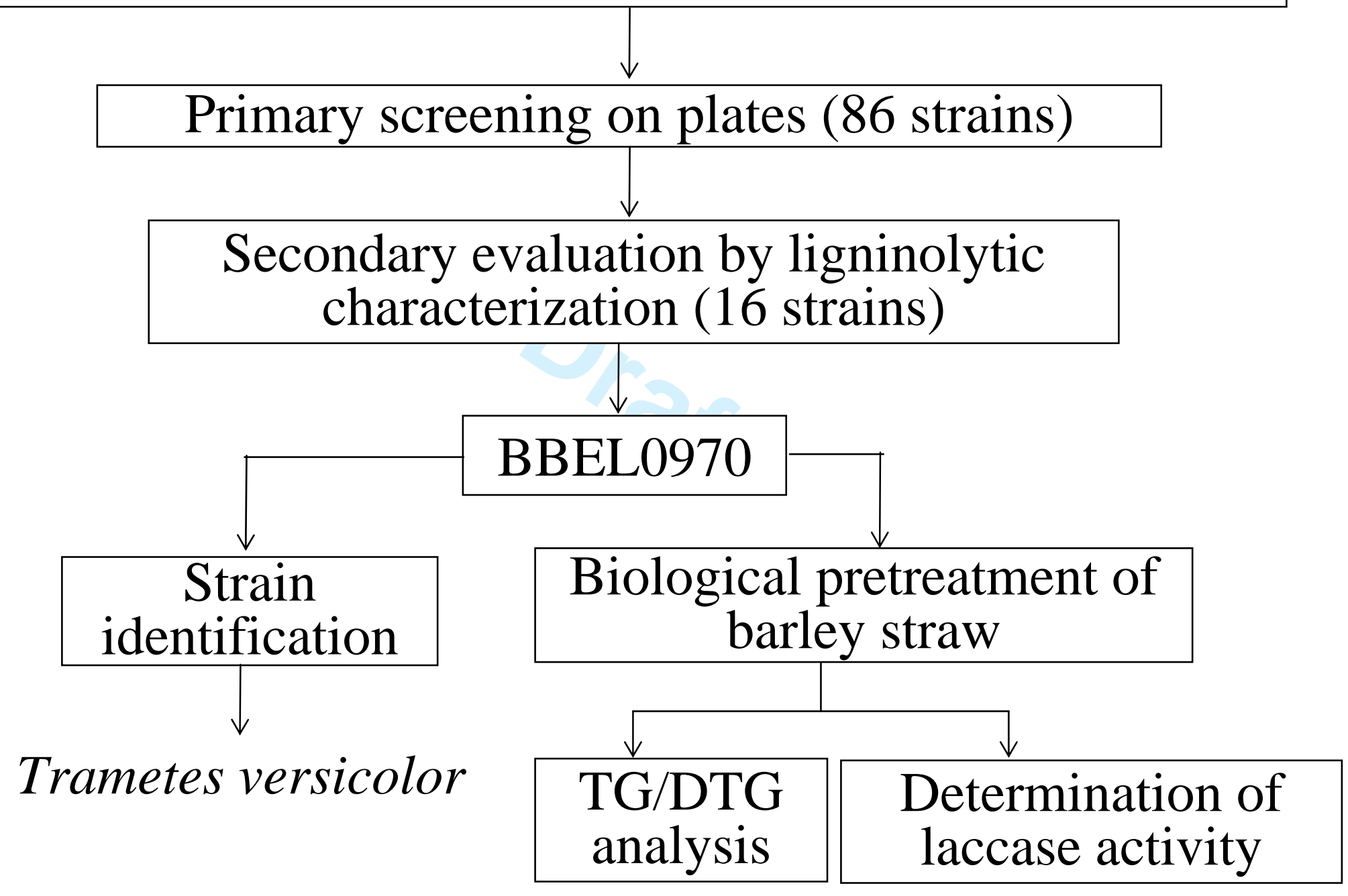




\section{(a)}

BBEL0902-Guaiacol:

(e)

(f)

(c)

BBEL0901-Poly R-478
BBEL0970-Guaiacol

\section{od}

(b)

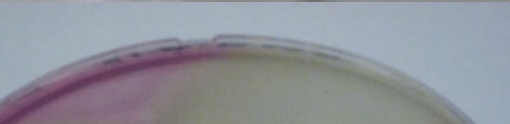

BB
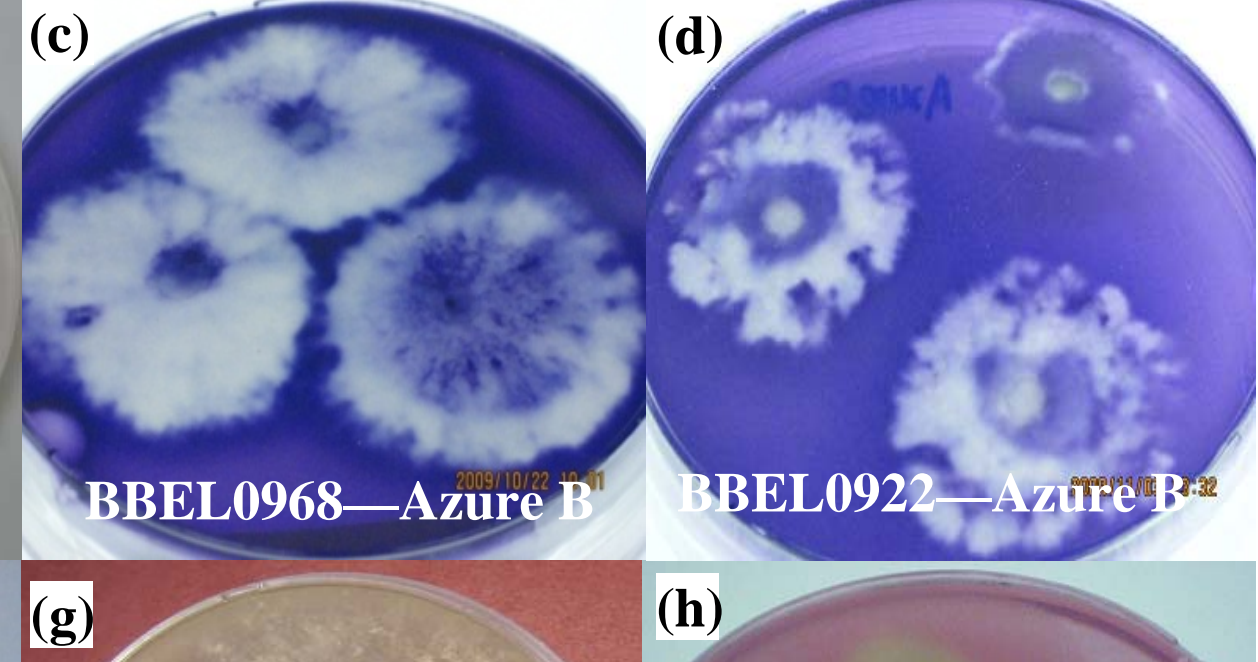

(h) 


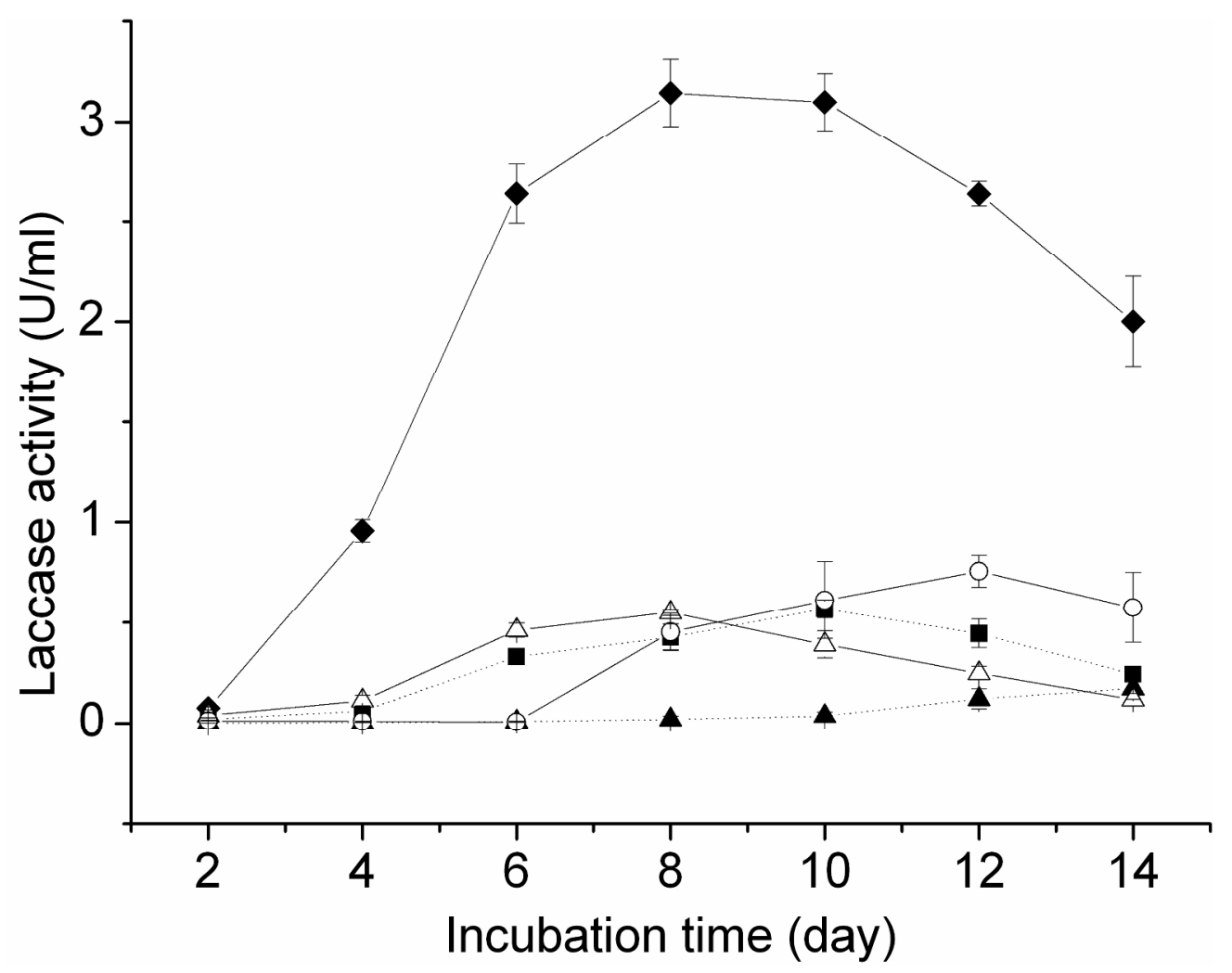

Fig. 3. Time courses of laccase activities in BLM $226 \times 177 \mathrm{~mm}(300 \times 300 \mathrm{DPI})$ 


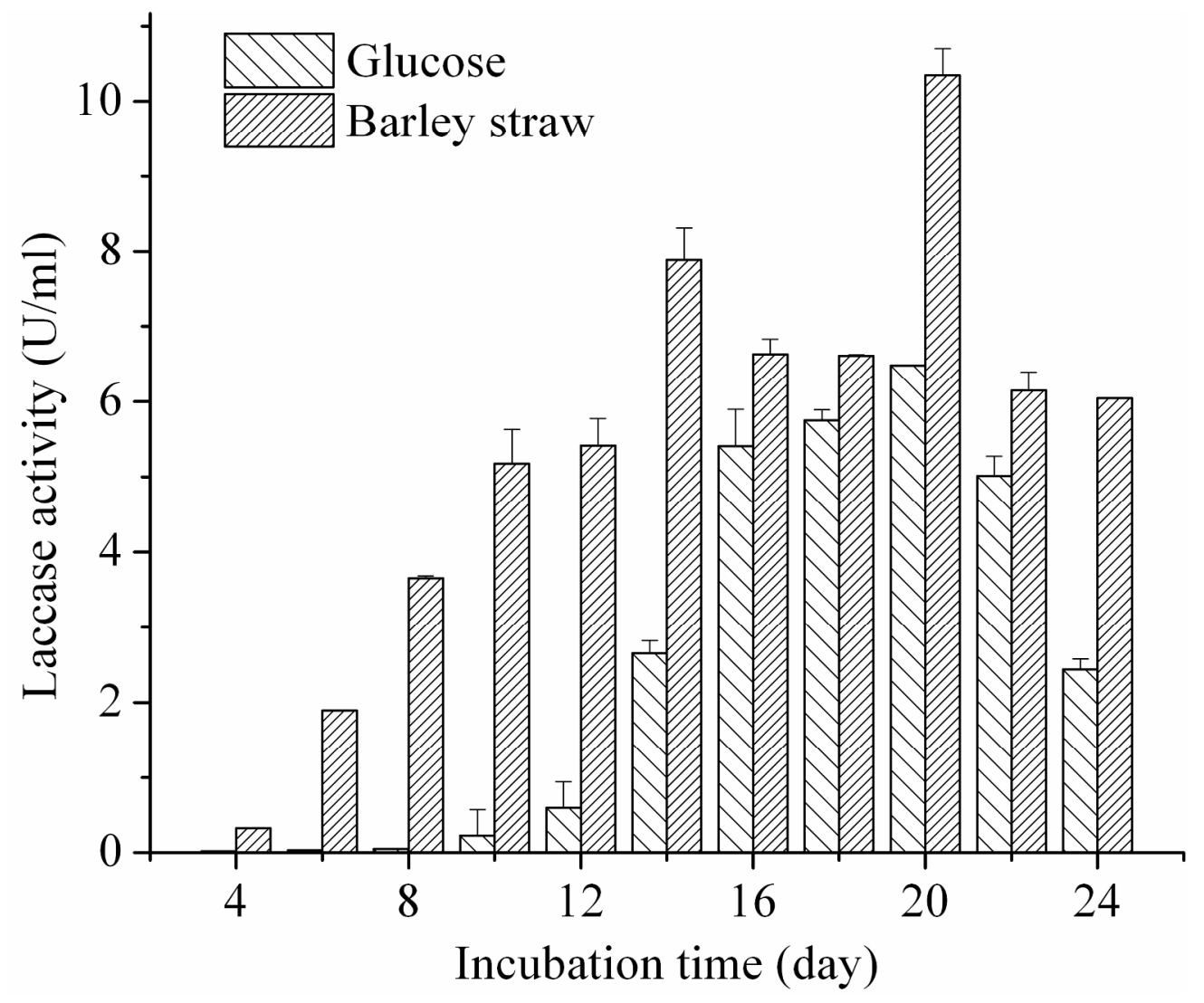

Fig. 4. Laccase production by BBEL0970 under different conditions with barley straw and glucose, respectively, as the sole carbon source in production media

$217 \times 181 \mathrm{~mm}$ (300 x $300 \mathrm{DPI})$ 
(A)

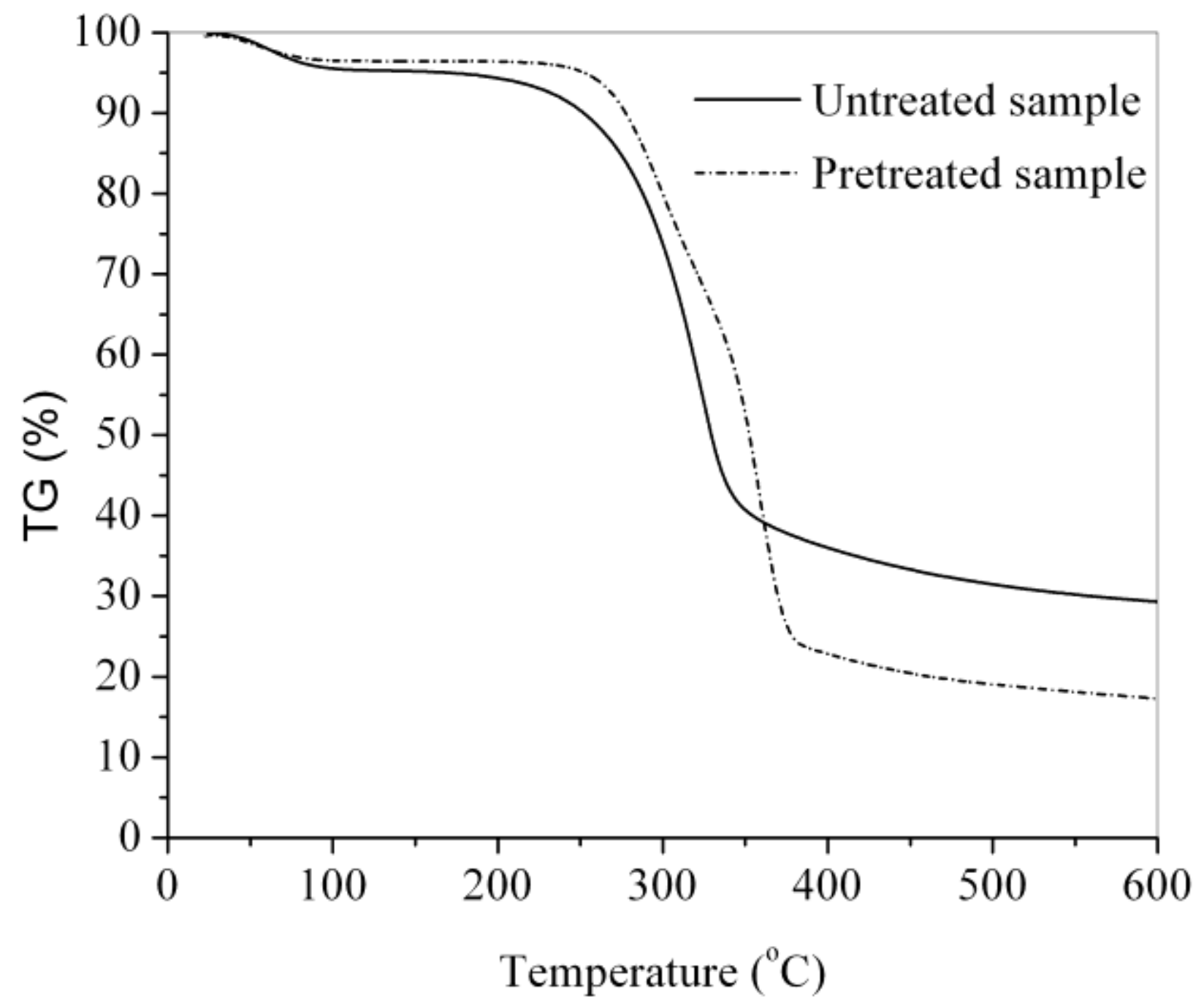


(B)

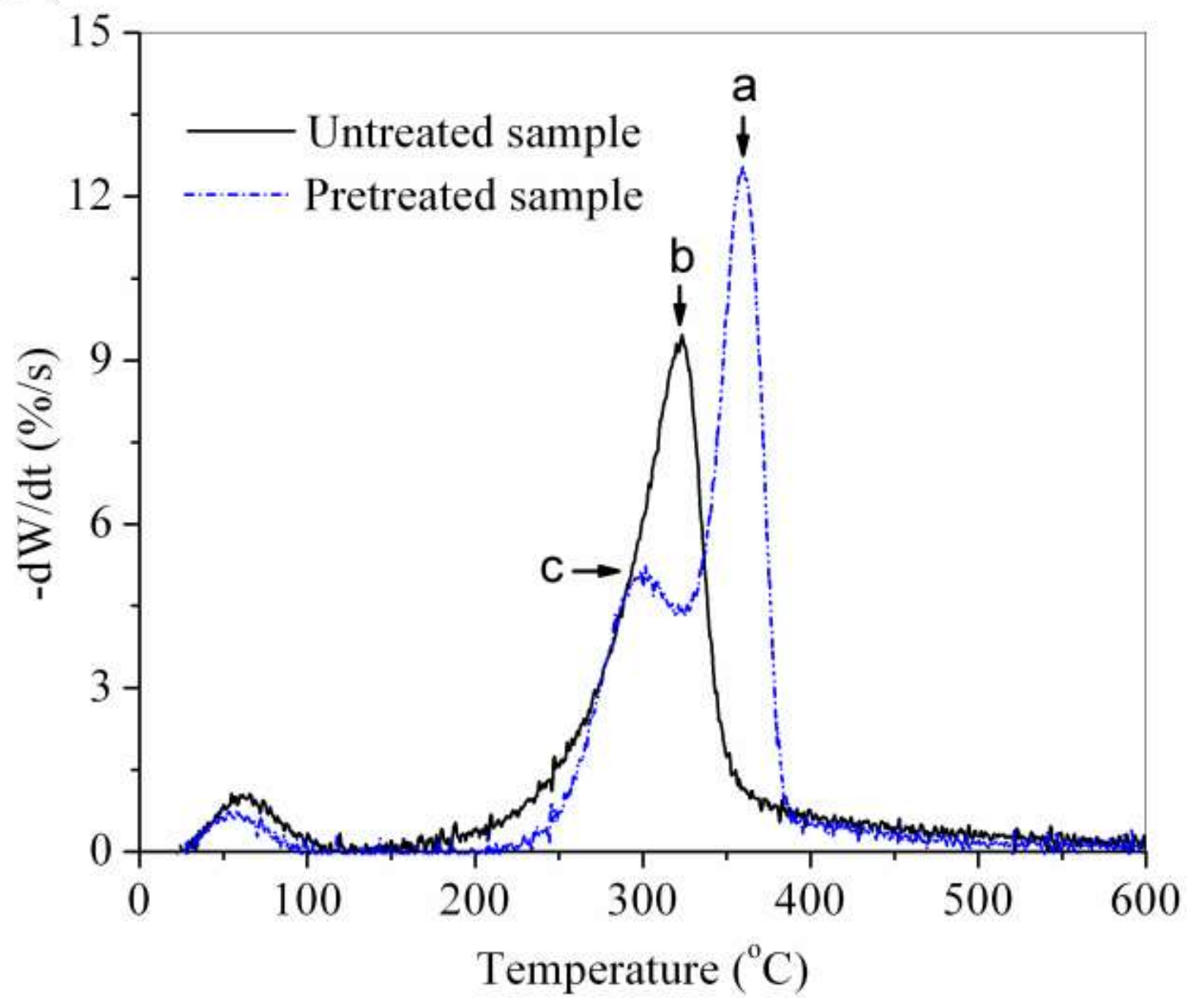


Phanerochaete chrysosporium AY219344

Antrodiella zonata FJ613652

Ceriporiopsis subvermispora FJ496695

Trametes trogii EU661876

86

Trametes lactinea GQ982888

96

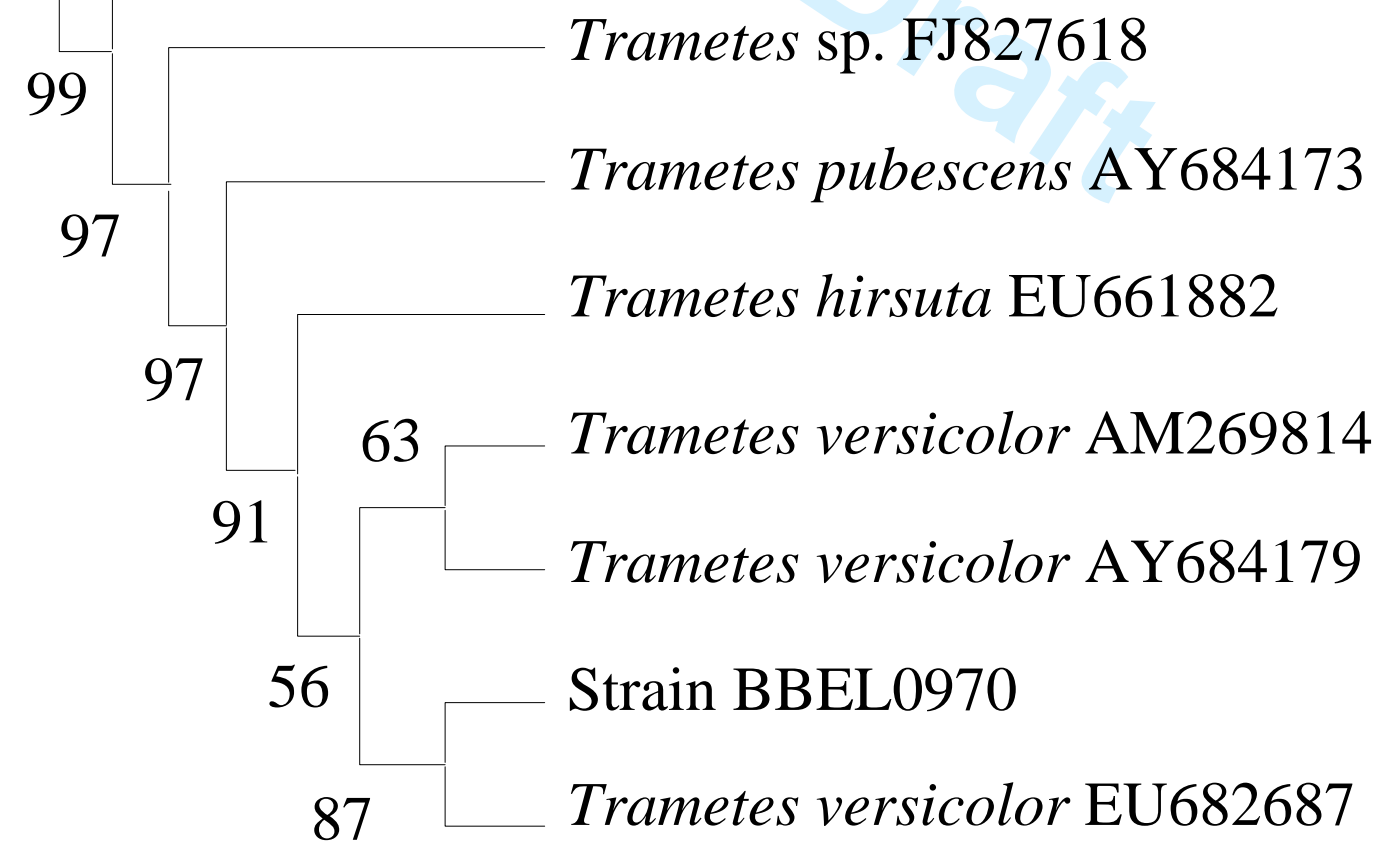

